\title{
Access and Waiting Time Standard for Early Intervention in Psychosis: At Risk Mental State Identification and In- terventions Accepted within a Routine Service
}

Vidyah Adamson, ${ }^{1 *}$ Steve Pitt, ${ }^{2}$ Caroline Wright, ${ }^{2}$ Rob Van Duyn, ${ }^{3}$ Mark Andrews, ${ }^{2}$ Katie Greathead, ${ }^{2}$ Sophie Brett, ${ }^{2}$ Stephen McConville, ${ }^{2}$ Lisa Jackson,, Jon Carroll, ${ }^{2}$ Kim Taylor, ${ }^{2}$ Emma Barrass, ${ }^{2}$ Chantelle Irikok, ${ }^{2}$ David Price, ${ }^{2}$ Simon Robertson, ${ }^{2}$ Simon Kettle, ${ }^{2}$ Amanda Graham ${ }^{2}$

${ }^{1}$ Nottinghamshire Healthcare NHS Foundation Trust, UK

${ }^{2}$ Lincolnshire Partnership NHS Foundation Trust, UK

${ }^{3}$ Nottinghamshire Healthcare Partnership NHS Foundation Trust, UK

\section{Abstract}

Aim: Following the introduction of an access and waiting time standard for Early Intervention in Psychosis (EIP) services, the identification and treatment of people experiencing an At-Risk Mental State (ARMS) for psychosis has become a national priority. However, there is a dearth of literature concerning what is offered to and accepted by ARMS service users within routine services.

Methods: This descriptive evaluation reports upon the assessment and treatment of people with an at-risk mental state identified during the first year of a routine service operating in line with the EIP standard. The paper details referral sources, referral to treatment times, socio-demographic characteristics, ARMS subgroups and the interventions accepted by these service users.

Results: A total of 138 ARMS cases were identified over the evaluation period, with 73\% ( $n=101$ ) aged between 18-34 years and 86\% ( $n=118$ ) meeting attenuated psychotic symptoms criteria. The majority (64\%) of service users engaged in multiple interventions; $54 \%(n=75)$ accepted psychoeducation and coping skills enhancement work, $42 \%(n=58)$ participated in a sleep programme, 33\% $(n=45)$ undertook coping with voices and visions work and $28 \%(\mathrm{n}=39)$ engaged in individual psychological therapy.

Conclusion: The findings indicate that the majority of ARMS service users presenting to the EIP service were aged 18-34 and experienced attenuated psychotic symptoms. A range of NICE and CBT informed interventions as well as individual psychological therapies appear to be acceptable to ARMS service users and many engaged in multiple interventions offered.

Keywords: Early intervention in psychosis, At risk mental state, Clinical high risk, Ultra high risk

\section{Introduction}

The onset of psychosis is typically preceded by a putative prodromal phase. This at-risk mental state (ARMS), variably termed clinical high risk or ultra-high-risk state for psychosis, is characterised by a range of non-specific behavioural and psychological symptoms, functional deterioration and attenuated psychotic symptoms or brief limited intermittent psychotic symptoms. ${ }^{1}$ Transition to psychosis for people meeting clinical high-risk criteria has been shown to be $21 \%$ at 1 year follow-up, $29 \%$ at 2 years and $36 \%$ at 3 years, which reflects a relative risk of around 500 times that of the general population. ${ }^{2}$

Given the detrimental impact of psychosis and psychotic disorders for individuals and their families across a range of clinical and functional outcomes ${ }^{3-8}$ and the significant fiscal burden schizophrenia poses to healthcare economies ${ }^{8,9}$ early detectionand treatment

\begin{tabular}{|l|l|}
\hline Quick Response Code: & Forresponding author: Vidyah Adamson, Early Intervention in Psychosis, 65 Northgate, \\
Newark, NG24 1HD, UK \\
Received: 02 March, 2021 \\
Citation: Vidyah A, Steve P, Caroline W, Rob VD, Mark A, et al. Access and Waiting Time Stan- \\
dard for Early Intervention in Psychosis: At Risk Mental State Identification and Interventions \\
Accepted within a Routine Service. J Psych Sci Res. 2021;1(1):1-7. DOI: \\
10.53902/JPSSR.2021.01.000501
\end{tabular}


for people experiencing an at-risk mental state is critical and has become a priority within the National Health Service (NHS) in England.

Early Intervention in Psychosis (EIP) services were established in England in the early 2000s with a specific remit to support people experiencing a first episode of psychosis (FEP) who were aged 14-35. People experiencing possible prodromal symptoms typically remained under the care of primary care services under a "watch and wait" brief. A study by Valmaggia ${ }^{10}$ highlighted cost-savings at 24 months within services able detect and treat people with an atrisk mental state. However, until relatively recently there have been few routine services embracing ARMS as part of their inclusion criteria. ${ }^{11,12}$ Consequently, people experiencing an at risk mental state have had little or no access to services or targeted clinical interventions.

In April 2016, an access and waiting time standard for EIP services in England was introduced ${ }^{13}$ with a rationale to ensure access to evidence-based interventions for people aged 14-65 experiencing a first episode of psychosis within a two-week time-frame; the standard was described as equally applicable to those experiencing an at-risk mental state in order to prevent transition to psychosis. ${ }^{13}$ Therefore, the remit of EIP services has been extended and it has become essential that these services are able to rapidly identify people experiencing an at-risk mental state and can offer treatments aiming to delay or prevent transition to psychosis.

A national survey found that the Comprehensive Assessment of at-risk Mental States ${ }^{14}$ has become the most widely used early detection assessment tool within England. ${ }^{15}$ The CAARMS supports the identification of three ARMS subgroups; vulnerability/genetic risk, attenuated psychotic symptoms and brief limited intermittent psychotic symptoms. There is a lack of literature apropos the numbers and subgroups of ARMS cases presenting to routine EIP services; however, meta-analytical evidence suggests that around 85\% of ARMS cases identified within research meet intake criteria owing to the presence of attenuated positive psychotic symptoms. ${ }^{16}$

Bearing in mind the relatively high proportion of false positives with respect to transition to psychosis, it has been proposed that ARMS interventions should have a benign profile, be well tolerated and acceptable to service users. ${ }^{17}$ However, there are scant details within the existing evidence-base regarding ARMS interventions offered in routine services which meet these criteria.

In terms of clinical guidance for services, the National Institute for Health and Care Excellence ${ }^{18}$ recommend that people at risk of developing psychosis are offered cognitive-behavioural therapy (CBT)with or without family intervention and that this group should not be offered antipsychotic medication aiming to prevent transition. Comorbid difficulties such as depression, anxiety, emerging personality disorder and substance misuse should be treated in line with the relevant NICE guidance.

There have been a number of randomised control trials of ARMS interventions, ranging from CBT to antipsychotic medication and omega-3 fatty acids. ${ }^{19-24}$ Meta-analytic studies using the outcome of transition to a psychotic disorder indicate that these ARMS interventions successfully delay or prevent the onset of psychosis at 12 months, however, preventative effects may diminish over time. ${ }^{25-27}$

A potentially promising paradigm involves targeting individual risk factors, such as sleep disturbance and worry, which have been associated with the onset and maintenance of specific psychotic experiences, such as persecutory delusions. ${ }^{28}$ Extending this approach and allied interventions to an ultra-high-risk group may have preventative benefits; ${ }^{29}$ however, this is yet to be investigated with transition to psychosis as an outcome.

There is a dearth of literature describing clinical interventions focused on delaying or preventing transition to psychosis within routine services and the acceptability of such interventions to service users. This evaluation describes the assessment and treatment of people identified as experiencing an risk mental state between $1^{\text {st }}$ April 2016 and $31^{\text {st }}$ March 2017 in a routine EIP service. Referral sources, referral to treatment times, socio-demographic characteristics and ARMS subgroups are reported. A description of the interventions that ARMS service users engaged with from the point of acceptance by the service until 31 $1^{\text {st }}$ March 2018 are also provided.

\section{Methods \\ Sample and setting}

The sample consisted of 138 individuals identified by the EIP service as experiencing an at-risk mental state between $1^{\text {st }}$ April 2016 and $31^{\text {st }}$ March 2017. ${ }^{30}$ The evaluation describes the interventions this cohort engaged with from acceptance by the service until $31^{\text {st }}$ March 2018.

The EIP service serves the needs of people living in Lincolnshire, a large rural county in the UK that has approximately 750,000 residents. ${ }^{31}$ The non-white population of Lincolnshire is circa $2.4 \%$, which is substantially smaller than the national average of $14 \% .32$ It is estimated that 2,428 people are living with a psychotic disorder within the county, ${ }^{31}$ with a predicted annual incidence of psychosis of $240 .{ }^{33}$ Adamson $^{30}$ found that the ratio of ARMS to FEP within Lincolnshire was approximately 1:1 for people presenting to the local EIP service.

Between $1^{\text {st }}$ April 2016 and 31 $1^{\text {st }}$ March 2017, the EIP service was integrated into six Community Mental Health Teams (CMHT), with the Clinical Lead and the CMHT Service Manager providing strategic, operational and clinical direction for the service. Between $1^{\text {st }}$ April 2017 and 31 $1^{\text {st }}$ March 2018, the approach to service delivery transformed to a stand-alone model of EIP provision, in which an EIP team coordinator managed day-to-day operational issues for the team and the Clinical Lead provided strategic and clinical oversight.

\section{Referral process}

Referrals are received from sources both internal and external to the provider organisation. Internal referrals can be made by any mental health team when there is a queried first episode of psychosis or at-risk mental state. Referrals external to the trust are received from GPs, educational establishments, family members and 
self-referrals are also accepted. All external referrals are received by the local Single Point of Access (SPA) team and are immediately flagged to the team via the electronic patient record system if there is a suspected psychosis.

\section{Assessment process}

Following referral, an EIP clinician establishes contact with the service user and the Primary Care Checklist (PCCL); ${ }^{34}$ is completed either face to face or over the telephone. The PCCL functions as an initial "screen and triage" and supports the team to assess the appropriateness of the referral and facilitates case prioritisation.

A positive screen using the PCCL leads to the patient being invited to an assessment appointment. A detailed clinical interview is conducted which is further supported the Comprehensive Assessment of at Risk Mental States (CAARMS) ${ }^{14}$ and the Social and Occupational Functioning Assessment Scale (SOFAS). ${ }^{35}$ Socio-demographic information is gathered including date of birth, gender, ethnicity and source of referral. A detailed description of the assessment tools employed within the service to identify ARMS cases and the threshold criteria for the subgroups within the CAARMS can be found within Adamson. ${ }^{30}$

\section{Interventions}

Post-assessment people identified as experiencing an at-risk mental state can access three broad categories of treatment:

1. NICE informed interventions and treatments

2. CBT-informed interventions

\section{Individual Psychological Therapies}

Interventions are discussed with the service user and offered in a sequential manner, with NICE informed interventions being offered first. If the service user declines the intervention offered or there are no clinical or functional improvements upon reassessment with the CAARMS14 and SOFAS35 then further intervention either within the same or next category of treatment are offered.

The service adopts a continuum view of psychosis and psychotic-like experiences given the frequency of such experiences in non-clinical populations. ${ }^{36-38}$ Hence, the focus of the ARMS interventions offered is on the promotion of mental wellbeing and stress/distress reduction.

\section{NICE recommended interventions and treatments}

NICE recommended interventions and treatments indicated for

Table 1: At risk mental state (ARMS) subgroup by age.

\begin{tabular}{|c|c|c|c|c|}
\hline & Arms vulnerability & Arms attenuated psychosis & Arms BLIPS & Arms total \\
\hline Age range & $\begin{array}{c}\text { (N/mean age } / \mathrm{SD} / \% \text { of } \\
\text { cases) }\end{array}$ & ( $\mathrm{N} /$ mean age $/ \mathrm{SD} / \%$ of cases) & $\begin{array}{c}\text { (N /mean age } / \mathrm{SD} / \% \\
\text { of cases) }\end{array}$ & $\begin{array}{c}\text { (N /mean age } / \mathrm{SD} / \% \text { of } \\
\text { cases) }\end{array}$ \\
\hline 14-17 years & $\begin{array}{c}0 \\
(\text { Mean=0) } \\
(\mathrm{SD}=0)\end{array}$ & $\begin{array}{c}7 \\
(\text { Mean=16.14) } \\
(S D=1.07)\end{array}$ & $\begin{array}{c}0 \\
(\text { Mean=0) } \\
(\mathrm{SD}=0)\end{array}$ & $\begin{array}{c}7 \\
(\text { Mean=16.14) } \\
(\mathrm{SD}=1.07) \\
(5.07 \%)\end{array}$ \\
\hline
\end{tabular}

psychosis including Behavioural Family Therapy (BFT), Individual Placement Support (IPS), Carer Support Programmes and Physical Health Assessment and Interventions are offered to people experiencing an at risk mental state. Pharmacological interventions, with the exception of antipsychotic medication, can be accessed by the service user; however, these interventions are not reported upon within the present evaluation. NICE interventions are delivered by a range of professionals including care coordinators, IPS workers, and CBT Therapists, psychology and psychiatry staff.

\section{Cognitive Behavioural Therapy (CBT) informed inter- ventions}

People experiencing an at-risk mental state are also offered the opportunity to engage in range of CBT-informed interventions, including psychoeducation and coping skills enhancement, the impact of substance use on mental wellbeing, coping with visions and voices, worry, ${ }^{39}$ sleep $^{40}$ and early warning signs action planning. These interventions are delivered by care coordinators who have received specific training and access regular clinical supervision.

\section{Individual psychological therapies}

Alongside, NICE recommended treatments and CBT-informed interventions, ARMS service users are able to engage in individual psychological therapies including CBT, trauma-focused CBT, Eye Movement Desensitization and Reprocessing (EMDR), meta-cognitive therapy and cognitive analytic therapy. These therapies are delivered by trained CBT Therapists and Psychologist within the service.

\section{Results}

\section{Referral sources and referral to treatment time}

During the first year of working in line with the EIP access and waiting time standard, the mean average referral to treatment time for the 138 ARMS cases identified was 2 weeks (SD 1.2), with a mean average of $68 \%(n=94)$ being seen within two weeks of the referral date.

$32 \%(n=44)$ of ARMS referrals came from GPs, 17\% $(n=23)$ from the Community Mental Health Teams, 13\% (n=18) from the Hospital Mental Health Liaison Service, $12 \%(n=17)$ from the Improving Access to Psychological Therapies teams, 10\% ( $\mathrm{n}=14$ ) from the Crisis Team, $6 \%(n=8)$ from Acute Inpatient Services, $6 \%(n=8)$ from Child and Adolescent Mental Health Services, 2\% (n=3) from the University Health Centre, $1 \%(n=2)$ from the Perinatal Mental Health Team and $1 \%(n=1)$ from another EIP team. 


\begin{tabular}{|c|c|c|c|c|}
\hline $18-34$ years & $\begin{array}{c}3 \\
(\text { Mean=21.01 } \\
(\mathrm{SD}=1.91)\end{array}$ & $\begin{array}{c}88 \\
(\text { Mean=22.79) } \\
(S D=4.47)\end{array}$ & $\begin{array}{c}10 \\
(\text { Mean=23.14) } \\
(\mathrm{SD}=3.92)\end{array}$ & $\begin{array}{c}101 \\
(\text { Mean=22.79) } \\
(\mathrm{SD}=4.47) \\
(73.19 \%)\end{array}$ \\
\hline $35-65$ years & $\begin{array}{c}0 \\
\text { Mean=0) } \\
(\mathrm{SD}=0)\end{array}$ & $\begin{array}{c}23 \\
(\text { Mean=44.73) } \\
(\mathrm{SD}=8.21)\end{array}$ & $\begin{array}{c}7 \\
(\text { Mean=41.86) } \\
(\mathrm{SD}=4.54)\end{array}$ & $\begin{array}{c}30 \\
(\text { Mean=44.73) } \\
(\mathrm{SD}=8.21) \\
(21.74 \%)\end{array}$ \\
\hline $\begin{array}{c}\text { TOTAL } \\
\text { (mean age/SD/\% of cases) }\end{array}$ & $\begin{array}{c}3 \\
(\text { Mean=21.01 } \\
(\mathrm{SD}=1.91) \\
-2.17 \%\end{array}$ & $\begin{array}{c}118 \\
(\text { Mean=27.23) } \\
(\mathrm{SD}=10.81) \\
-85.51 \%\end{array}$ & $\begin{array}{c}17 \\
(\text { Mean=27.51) } \\
(\mathrm{SD}=8.61) \\
-12.32 \%\end{array}$ & $\begin{array}{c}138 \\
(\text { Mean=27.23) } \\
(\mathrm{SD}=10.81) \\
(100 \%)\end{array}$ \\
\hline
\end{tabular}

\section{Age and ARMS subgroups}

Of the 138 ARMS cases; $86 \%(n=118)$ met criteria for ARMS attenuated psychosis, 12\% ( $\mathrm{n}=17)$ met ARMS brief limited intermittent psychotic symptoms (BLIPS) criteria and $2 \%(n=3)$ met ARMS vulnerability criteria. The mean age of the 138 ARMS cases was 27.2 ( $S D=10.81) .5 \%(n=7)$ were aged $14-17$ years with a mean age of 16.14 (SD=1.07), 73\% ( $\mathrm{n}=101)$ were between $18-34$ years old with a mean age of $22.79(\mathrm{SD}=4.47)$ and $22 \%(\mathrm{n}=30)$ were with the 35 65 years age range and had a mean age of 44.73 years (SD=8.21). Table 1 provides a breakdown of ARMS subgroups by age.

Table 2: At risk mental state (ARMS) subgroup by gender.

\begin{tabular}{|c|c|c|c|c|}
\hline \multirow{2}{*}{ Gender } & Arms vulnerability & Arms attenuated psychosis & Arms BLIPS & Arms Total \\
\cline { 2 - 5 } & $\mathbf{N}$ & $\mathbf{N}$ & $\mathbf{N}$ & $\mathbf{N}(\%$ of total cases $)$ \\
\hline Male & 2 & 74 & 13 & $(14.60 \%)$ \\
\hline (\% of total cases $)$ & $(2.24 \%)$ & $(83.14 \%)$ & 4 & 49 \\
\hline Female & 1 & 44 & $(8.16 \%)$ & $(35.51 \%)$ \\
\hline (\% of total cases $)$ & $(2.04 \%)$ & $(89.79 \%)$ & 17 & 138 \\
TOTAL & 3 & 118 & $(12.32 \%)$ & $(100 \%)$ \\
\hline
\end{tabular}

\section{Ethnicity and ARMS subgroup}

Of the 138 ARMS cases, 76\% ( $\mathrm{n}=105)$ identified themselves as White British, $18 \%(n=25)$ were of unknown ethnic origin, $4 \%$

Table 3: At risk mental state (ARMS) subgroup by ethnicity.

\begin{tabular}{|c|c|c|c|c|}
\hline \multirow{2}{*}{ Ethnicity } & Arms vulnerability & Arms attenuated psychosis & Arms BLIPS & Arms Total \\
\cline { 2 - 5 } & $\boldsymbol{N}$ & $\boldsymbol{N}$ & $\boldsymbol{N}$ & $\mathbf{N}(\%$ of total cases $)$ \\
\hline African & 0 & 0 & 0 & 1 \\
\hline Black Other & 0 & 1 & $0.73 \%)$ & $(0.73 \%)$ \\
\hline Chinese & 0 & 1 & 1 & $(0.73 \%)$ \\
\hline White - British & 3 & 90 & 12 & 105 \\
\end{tabular}

Of the 138 ARMS cases $65 \%(n=89)$ self-identified as male and $36 \%(n=49)$ as female. Of 89 that identified as male, $2 \%(n=2)$ met ARMS vulnerability criteria, $83 \%(n=74)$ met the threshold for ARMS attenuated psychosis and 15\% $(n=13)$ met the criteria for ARMS BLIPS group. Of the 49 people that identified as female, 2\% $(n=1)$ met ARMS vulnerability criteria, 90\% $(n=44)$ met the threshold for ARMS attenuated psychosis and $8 \%(n=4)$ met the criteria for ARMS BLIPS group. Table 2 provides a breakdown of ARMS subgroups by gender. were identified as White Other, $1 \%(n=1)$ identified as African, 1\% $(\mathrm{n}=1)$ identified as Black Other and $1 \%(\mathrm{n}=1)$ identified as Chinese. Table 3 provides a breakdown of ethnicity by ARMS subgroups by ethnicity.

\section{Gender and ARMS subgroup}




\begin{tabular}{|c|c|c|c|c|}
\hline White - Other & 0 & 5 & 0 & 5 \\
\hline Unknown & 0 & 21 & 4 & 25 \\
\hline Total & 3 & 118 & 17 & $(18.12 \%)$ \\
\hline (\% of total cases) & $(2.17 \%)$ & $(85.51 \%)$ & $(12.32 \%)$ & 138 \\
\hline
\end{tabular}

\section{Interventions and ARMS subgroups}

$64 \%(n=138)$ of ARMS service users engaged in two or more interventions during the evaluation period. The mean average number of interventions engaged with per service user was 4.79

Table 4: Interventions engaged with by ARMS subgroup.

\begin{tabular}{|c|c|c|c|c|}
\hline \multirow{2}{*}{ Ethnicity } & Arms vulnerability & Arms attenuated psychosis & Arms BLIPS & Arms Total \\
\hline & $\mathbf{N}$ & $\mathbf{N}$ & $\mathbf{N}$ & $\mathrm{N}(\%$ of total cases $)$ \\
\hline $\begin{array}{c}\text { Behavioural Family } \\
\text { Therapy }\end{array}$ & 0 & 8 & 1 & $\begin{array}{c}9 \\
(6.52 \%)\end{array}$ \\
\hline $\begin{array}{c}\text { Individual Placement } \\
\text { Support }\end{array}$ & 1 & 11 & 0 & $\begin{array}{c}12 \\
(8.70 \%)\end{array}$ \\
\hline $\begin{array}{l}\text { Physical Health Assess- } \\
\text { ment and Intervention }\end{array}$ & 1 & 32 & 3 & $\begin{array}{c}36 \\
(26.09 \%)\end{array}$ \\
\hline Carer Support & 0 & 5 & 1 & $\begin{array}{c}6 \\
(4.35 \%)\end{array}$ \\
\hline $\begin{array}{l}\text { Psychoeducation and } \\
\text { Coping Skills Enhance- } \\
\text { ment }\end{array}$ & 2 & 67 & 6 & $\begin{array}{c}75 \\
(54.35 \%)\end{array}$ \\
\hline $\begin{array}{l}\text { Substance Use Inter- } \\
\text { vention }\end{array}$ & 1 & 15 & 5 & $\begin{array}{c}21 \\
(15.22 \%)\end{array}$ \\
\hline Worry & 2 & 25 & 0 & $\begin{array}{c}27 \\
(19.57 \%)\end{array}$ \\
\hline Sleep & 3 & 48 & 7 & $\begin{array}{c}58 \\
(42.03 \%)\end{array}$ \\
\hline $\begin{array}{l}\text { Coping with Voices and } \\
\text { Visions }\end{array}$ & 1 & 39 & 5 & $\begin{array}{c}45 \\
(32.61 \%)\end{array}$ \\
\hline $\begin{array}{l}\text { Early Warning Signs } \\
\text { and Action Planning }\end{array}$ & 1 & 31 & 5 & $\begin{array}{c}37 \\
(26.82 \%)\end{array}$ \\
\hline $\begin{array}{l}\text { 1:1 Psychological } \\
\text { Therapy }\end{array}$ & 2 & 34 & 3 & $\begin{array}{c}39 \\
(28.26 \%)\end{array}$ \\
\hline $\begin{array}{c}\text { Total } \\
\mathrm{N}(\% \text { of total cases })\end{array}$ & $3(2.17 \%)$ & $11(85.51 \%)$ & $17(12.32 \%)$ & $\begin{array}{c}123 \\
(100 \%)\end{array}$ \\
\hline
\end{tabular}

Of the NICE informed interventions offered within the service, $26 \%(n=36)$ accessed physical health assessments and interventions, $9 \%(n=12)$ engaged in IPS work to seek paid employment, $7 \%(n=9)$ engaged in Behavioural Family Therapy and $4 \%(n=6)$. It is important to note that BFT was only introduced to the service three months prior to the end of the evaluation period and this will have influenced the number of people able to access this intervention as reported within this paper.
$(S D=2.15)$ with a range between 2-12 interventions being taken up. Engagement within the present study is operationalised as attending two or more specific intervention sessions. Table 4 provides a detailed breakdown of interventions engaged with by ARMS subgroup. 
$28 \%(n=39)$ of ARMS service users engaged in 1:1 psychological therapy. Unfortunately, during the evaluation period the electronic patient record system utilised to gather the data changed within the provider organisation and this led to the specific details of the individual therapies engaged with becoming inaccessible. It is likely that the number of ARMS service users accessing 1:1 psychological therapy would have been higher with greater capacity within the service as evidence by the internal waiting list for these interventions.

\section{Discussion}

The advent of the access and waiting time standard for EIP services has led to an expectation that these services will identify and treat people experiencing an at risk mental state for psychosis in a timely manner. ${ }^{32}$ Consequently, the present evaluation reports upon referral sources, referral to treatment times, socio-demographic characteristics and ARMS subgroups presenting to a routine EIP service.

In terms of access and waits, the majority of referrals came from GPs, highlighting a need for EIP services to develop close working relationships with primary care and facilitate training focused on ARMS for referrers. ${ }^{41,42}$ The service provided assessment and interventions within two weeks for the majority of service users, which may increase the prospect of early amelioration and/or elimination of putative prodromal symptoms.

In line with other studies, a high number of service users met attenuated psychotic symptoms criteria. ${ }^{43}$ The comparatively low numbers of people meeting ARMS vulnerability and BLIPS criteria may indicate a possible limitation with respect to current assessment methods as people presenting with non-psychotic putative prodromal symptoms may not be easily recognised as at risk by referrers and assessing clinicians. ${ }^{44}$

Ethical concerns with respect to intervening with people who meet ultra-high-risk criteria and may never develop psychosis, has led to recommendations that the clinical management of this group should be limited to those who seek help for distressing and debilitating symptoms such as depression and / or anxiety in the context of psychotic experiences. ${ }^{45}$ Furthermore, interventions offered should be benign, well tolerated and acceptable to service users. ${ }^{17}$

The results of this evaluation suggest that a range of NICE and CBT informed interventions as well as individual psychological therapies are deemed acceptable by people with an at-risk state. Most chose to engage with multiple interventions offered within the service with an average of 4-5 interventions per service user. These findings indicate that routine services may experience a high demand for ARMS interventions hence the capacity to meet this will require careful consideration and planning between providers and commissioners. Furthermore, this highlights a workforce training need as it has been suggested that if ARMS interventions are not delivered with skill and expertise then there may be a paradoxical effect of increasing the rate of transition. ${ }^{46}$

Historically, EIP has focused on first episode psychosis in 14-35-year-olds and these services have demonstrated a range of positive clinical, functional and economic outcomes when compared to standard care ${ }^{47-50}$ It is unclear if extending the access criteria of routine EIP services to embrace ARMS will impact on these positive outcomes ${ }^{30}$ nor is it clear whether ARMS interventions delivered within real-world services decreases putative prodromal symptoms and transition to psychosis. This will require future evaluation.

\section{Acknowledgments}

None.

\section{Funding}

None.

\section{Conflicts of interest}

Author declares that there is no conflict of interest.

\section{References}

1. Ruhrmann S, Schultze-Lutter F, Salokangas R, et al. Prediction of psychosis in adolescents and young adults at high risk: results from the prospective European prediction of psychosis study. Archives of General Psychiatry. 2010;67(3):241-251.

2. Fusar-Poli P, Bonoldi I, Yung AR, et al. Predicting psychosis: metaanalysis of transition outcomes in individuals at high clinical risk. Arch Gen Psychiatry. 2012;69(3):220-229.

3. Onwumere J, Sirykaite S, Schulz J, et al. Understanding the experience of "burnout" in first-episode psychosis carers. Compr Psychiatry. 2018;83:19-24.

4. Leucht S, Burkard T, Henderson J, et al. Physical illness and schizophrenia: a review of the literature. Acta Psychiatr Scand. 2007;116(5):317-333.

5. Wahlbeck K, Westerman J, Nordentotft M, et al. Outcomes of Nordic mental health systems: Life expectancy of patients with mental disorders. British Journal of Psychiatry. 2011;199:453-458.

6. Allardyce J, Van Os J. Long-term course and outcome of schizophrenia. Psychiatry. 2018;7(10):440-442.

7. Marwaha S, Johnson S. Schizophrenia and employment - a review. Soc Psychiatry PsychiatrEpidemiol. 2004;39(5):337-349.

8. Schizophrenia Commission. Effective Interventions in Schizophrenia: The Economic Case. London. 2012.

9. Royal College of Psychiatrists. Report of the National Audit of Schizophrenia (NAS). London. 2012.

10. Valmaggia LR, McCrone P, Knapp M, et al. Economic impact of early intervention in people at high risk of psychosis. Psychol Med. 200;39(10):1617-1626.

11. Marwaha S, Thompson A, Upthegrove R, et al. Fifteen years on - early intervention for a new generation. Br J Psychiatry. 2016;209(3):186188.

12. Thompson A, Marwaha S, Broome MR. At risk mental state for psychosis: identification and current treatment approaches. BJPsych Advances. 2016;22:86-193.

13. National Institute for Health and Care Excellence. Implementing the Early Intervention in Psychosis Access and Waiting Time Standard: Guidance. NHS England Publications, London. 2016.

14. Yung AR, Yuen HP, McGorry PD, et al. Mapping the onset of psychosis: the Comprehensive Assessment of At-Risk Mental States. Aust N Z J Psychiatry. 2005;39(11-12):964-971.

15. Stain HJ, Mawn L, Common S, et al. Research and practice for ultra-high risk for psychosis: A national survey of early intervention in psychosis services in England. Early Interv Psychiatry. 2019;13(1):47-52. 
16. Fusar-Poli P, Cappucciati M, Borgwardt S, et al. Heterogeneity of Psychosis Risk Within Individuals at Clinical High Risk: A Metaanalytical Stratification. JAMA Psychiatry. 2016;73(2):113-120.

17. Davies C, Radua J, Cipriani A, et al. Efficacy and Acceptability of Interventions for Attenuated Positive Psychotic Symptoms in Individuals at Clinical High Risk of Psychosis: A Network Meta-Analysis. Front Psychiatry. 2018;9:187.

18. National Institute for Health and Care Excellence. Psychosis and Schizophrenia in Adults: Prevention and Management. 2014.

19. Morrison AP, French P, Walford L, et al. Cognitive therapy for the prevention of psychosis in people at ultra-high risk: randomised controlled trial. Br J Psychiatry. 2004;185:291-297.

20. Morrison AP, French P, Stewart SLK, et al.Early detection and intervention evaluation for people at risk of psychosis: Multisite randomised controlled trial. BMJ. 2012;344:e2233.

21. van der Gaag M, Nieman DH, Rietdijk J, et al. Cognitive behavioral therapy for subjects at ultrahigh risk for developing psychosis: a randomized controlled clinical trial. Schizophr Bull. 2012;38(6):1180-1188.

22. McGorry PD, Yung AR, Phillips LJ, et al. Randomized controlled trial of interventions designed to reduce the risk of progression to first-episode psychosis in a clinical sample with subthreshold symptoms. Arch Gen Psychiatry. 2002;59(10):921-928.

23. McGlashan TH, Zipursky RB, Perkins D, et al. Randomized, double-blind trial of olanzapine versus placebo in patients prodromally symptomatic for psychosis. Am J Psychiatry. 2006;163(5):790-799.

24. Amminger GP, Schäfer MR, Papageorgiou K, et al. Long-chain omega-3 fatty acids for indicated prevention of psychotic disorders: a randomized, placebo-controlled trial. Arch Gen Psychiatry. 2010;67(2):146-154.

25. Preti A, Cella M. Randomized-controlled trials in people at ultra high risk of psychosis: a review of treatment effectiveness. Schizophr Res. 2010;123(1):30-36.

26. Stafford MR, Jackson H, Mayo-Wilson E, et al. Early interventions to prevent psychosis: systematic review and meta-analysis, BMJ. 2013;346:f185

27. van der Gaag M, Smit F, Bechdolf A, et al. Preventing a first episode of psychosis: meta-analysis of randomized controlled prevention trials of 12 month and longer-term follow-ups. Schizophr Res. 2013;149(13):56-62.

28. Freeman D, Stahl D, McManus S, et al. Insomnia, worry, anxiety and depression as predictors of the occurrence and persistence of paranoid thinking. Soc Psychiatry PsychiatrEpidemiol. 2011;47(8):1195-1203.

29. Bradley J, Freeman D, Chadwick E, et al. Treating Sleep Problems in Young People at Ultra-High Risk of Psychosis: A Feasibility Case Series. BehavCognPsychother. 2018;46(3):276-291.

30. Adamson V, Barrass E, Mc Conville S, et al. Implementing the access and waiting time standard for early intervention in psychosis in the United Kingdom: An evaluation of referrals and post-assessment outcomes over the first year of operation. Early Interv Psychiatry. 2018;12(5):979-986.

31. Lincolnshire Research Observatory. A Mental Illness Health Needs Assessment for Lincolnshire. 2016.

32. Lincolnshire Research Observatory. Country of Birth, Ethnicity and Nationality of Lincolnshire Residents. 2011.

33. Kirkbride JB, Errazuriz A, Croudace TJ, et al. Systematic review of the incidence and prevalence of schizophrenia and other psychoses in England. London: Department of Health, Policy Research Programme. 2012.
34. French P, Owens J, Parker S, et al. Identification of young people in the early stages of psychosis: Validation of a checklist for use in primary care. Psychiatry Research, 2012;200:911-916.

35. Goldman HH, Skodol AE, Lave TR. Revising axis V for DSM-IV: a review of measures of social functioning. Am J Psychiatry. 1992;149(9):11481156.

36. Verdoux H, van Os J. Psychotic symptoms in non-clinical populations and the continuum of psychosis. Schizophr Res. 2002;54(1-2):59-65.

37. Kelleher I, Cannon M. Psychotic-like experiences in the general population: characterizing a high-risk group for psychosis. Psychol Med. 2011;41(1):1-6.

38. Rössler W, Riecher-Rössler A, Angst J, et al. Psychotic experiences in the general population: a twenty-year prospective community study. Schizophr Res. 2007;92(1-3):1-14.

39. Freeman D, Dunn G, Startup H, et al. Effects of cognitive behaviour therapy for worry on persecutory delusions in patients with psychosis (WIT): a parallel, single-blind, randomised controlled trial with a mediation analysis. Lancet Psychiatry. 2015a;2(4):305-313.

40. Freeman D, Waite F, Startup H, et al. Efficacy of cognitive behavioural therapy for sleep improvement in patients with persistent delusions and hallucinations (BEST): a prospective, assessor-blind, randomised controlled pilot trial. Lancet Psychiatry. 2015b;2(11):975-983.

41. Reynolds N, Wuyts P, Badger S, et al. The impact of delivering GP training on the clinical high risk and first-episode psychosis on referrals and pathways to care. Early Interv Psychiatry. 2015;9(6):459-466.

42. Broome MR, Woolley JB, Johns LC, et al. Outreach and support in south London (OASIS): implementation of a clinical service for prodromal psychosis and the at risk mental state. Eur Psychiatry. 2005;20(56):372-378.

43. Fusar-Poli P, Byrne M, Badger S, et al. Outreach and support in south London (OASIS), 2001-2011: ten years of early diagnosis and treatment for young individuals at high clinical risk for psychosis. Eur Psychiatry. 2013;28(5):315-326.

44. Valmaggia LR, McCrone $\mathrm{P}$, Knapp $\mathrm{M}$, et al. Economic impact of early intervention in people at high risk of psychosis. Psychol Med. 200;39(10):1617-1626.

45. McGuire PK. Prodromal intervention: the need for evaluation. Journal of Mental Health. 2002;11:469-470.

46. Thompson A, Marwaha S, Broome MR. At risk mental state for psychosis: identification and current treatment approaches. BJPsych Advances. 2016;22:86-193.

47. Bird V, Premkumar P, Kendall T, et al. Early intervention services, cognitive-behavioural therapy and family intervention in early psychosis: systematic review. BrJ Psychiatry. 2010;197(5):350-356.

48. Mihalopoulos C, Harris M, Henry L, et al. Is early intervention in psychosis cost-effective over the long term? Schizophr Bull. 2009;35(5):909-918.

49. McCrone P, Park A, Knapp M. Economic evaluation of early intervention (EI) services, phase IV report. PSSRU discussion paper. 2010;2745.

50. Fowler D, Hodgekins J, Howells L, et al. Can targeted early intervention improve functional recovery in psychosis? A historical control evaluation of the effectiveness of different models of early intervention service provision in Norfolk 1998-2007. Early Interv Psychiatry. 2009;3(4):282-8. 